\title{
Endovascular Management of the Failure of Maturation of Native Arterio- Venous Fistula due to Outflow Stenosis for Hemodialysis
}

Amr Bakr El-Ashry ${ }^{1, * M S c}$, Ashraf Mohamed Ewida ${ }^{2}$ MD and Almetwaly Ragab Ibrahim ${ }^{1}$ MD.

\author{
*Corresponding Author: \\ Amr Bakr El-Ashry \\ dr.a.bakr.avc@gmail.com

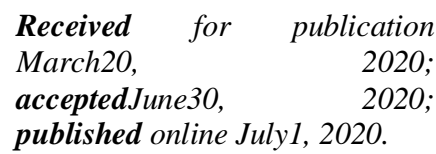

\subsection{8/aimj.2020.26253.1175}

Copyright 2020 The Authors published by Al-Azhar University, Faculty of Medicine, Cairo, Egypt. All rights reserved. This an openaccess article distributed under the legal terms, where it is permissible to download and share the work provided it is properly cited. The work cannot be changed in anyway or used commercially.

doi:10.21608/aimj.2020.26253.1175

${ }^{1}$ Vascular Surgery Department, Faculty of Medicine, Al-Azhar University, Damietta, Egypt.

${ }^{2}$ Vascular Surgery Department, Faculty of Medicine, Al-Azhar University, Cairo, Egypt.

\begin{abstract}
Background: Arteriovenous fistula (AVF) is a significant procedure for patient in need of hemodialysis. Failure of maturation due to stenosis is a challenge that needs further intervention. Endovascular treatment allows salvaging these fistulae.

Aim of the work: To identify the anatomical causes of maturation failure and to assess immediate and long-term clinical effects of PTA of non-mature native (AVF) caused by outflow stenosis using currently available endovascular techniques.

Material and Methods: This study was performed on forty patients complaining of stenosis of primary AVF. The mean age is 60.5 .

Patients were followed-up every two weeks for the first 2 months, then every month for 6 months post-intervention clinically and radiologically. Collected data includes patient's demographics, cause of renal failure, characters of primary AVF, and variables of endovascular intervention, primary patency, and recurrence of stenosis.

Results: AVF type was either brachiocephalic (57.5\%), brachiobasilic $(32.5 \%)$ or radiocephalic $(10.0 \%)$. Fistulography revealed peripheral venous stenosis in 18 patients $(45.0 \%)$, central venous stenosis in 14 patients (35.0\%), and juxta-anastomotic stenosis in 8 patients (20\%). Our technical success was achieved in $87.5 \%$ of cases; the patency rate was $91.0 \%$ in a month, $86.0 \%$ in 3 months, and $80.0 \%$ in 6 months. Complications were reported in 10 cases. The recurrence was reported in 7 patients (17.5\% of cases).

Conclusions: Endovascular salvage of failing A-V fistulas with PTA and Stenting is safe and effective. It is associated with high success rates, low complication rates, and rendering the immediate reuse of the failing shunt.

Keywords: Arteriovenous fistula; Endovascular; Hemodialysis; Nonmaturation; Outflow Stenosis.
\end{abstract}

\section{INTRODUCTION}

Chronic end-stage renal disease (ESRD) patients need replacement renal therapy. Native arteriovenous fistula (AVF) is considered as the primary and best vascular access method for renal hemodialysis. ${ }^{1}$

In comparison with synthetic grafts and central vein catheters, the native AVF is associated with a low rate of complications, had a low revision rate, costs $^{2}$, and low mortality rate. ${ }^{3}$ On the other side, AVF had the disadvantage of being associated with a relatively high rate of failure of maturation and early thrombosis. The main causes of AVF maturation failure are arterial or venous problems and the presence of accessory vein. AVF failure of maturation could be early or late; early failure applies to fistula that is never used for dialysis or fails within 3 months of its first use. ${ }^{4}$ Late failure refers to failure after 3 months of successful use. ${ }^{5}$

The reported rate is extending between 24 and $60 \%$ of failure to mature in studies from American and European hemodialysis patient, respectively. ${ }^{6-9}$

Thus, native arterio-venous fistulae (AVF) failure of maturation is a challenging matter in the establishment of functioning hemodialysis vascular access. Current recommendations are monitoring newly created fistula closely to discover maturation; and if happened, early intervention is recommended. However, there was no consensus on the ideal intervention to enhance AVF. ${ }^{10}$

The aim of the work was to identify the anatomical causes of maturation failure and to assess immediate and long-term clinical effects of PTA of non-mature 
native (AVF) caused by outflow stenosis using currently available endovascular techniques.

\section{PATIENTS AND METHODS}

\section{Patients:}

A total of 40 patients with chronic end-stage renal disease, who had dysfunction (stenosis) of primary native AVF were involved in the present research. The mean age is 60.5 . 25 males and 15 females are included. The study was conducted during the period from November 2017 to November 2019. Patients were followed up every two weeks for the first 2 months clinically and radiologically, then follow-up was initiated at intervals of 3 months through telephone contact with either the patient or the hemodialysis center for 6 months post-intervention according to follow up protocol adopted by the vascular surgery department for such patient and the last case was concluded in our study in April 2019 as a period of our follow up was 6 months. Patients enrolled in this study were selected according to the presence of one or more of the inclusion criteria.

\section{Inclusion criteria:}

Patient with immature autogenous arteriovenous fistula in the upper arm or forearm which never used or fails during the first 3 months of the use had clinical and radiographic signs of outflow stenosis (peripheral and central venous stenosis ) such as weak thrill, low rates of flow, post AV access hypertension and arm edema.

\section{Exclusion criteria:}

includes patient with thrombosed arterio-venous fistula with no thrill palpable by physical examination and ultrasound, evidence of arteriovenous fistula -related infection, patient with a history of an extreme allergic reaction to intravenous radiographic contrast substances, patient who unable perform the treatment, non-correctable cause of immaturation as (Heart Failure), pseudo-aneurysm and steel syndrome.

\section{Methods:}

The study protocol was accepted by the local research and ethics committee of Al-Azhar faculty of Medicine (Cairo). All patients signed an informed consent after full explanation of the study protocol .

Their data privacy and withdrawal right were ascertained. Collected data includes patient's demographics (age, gender), causes of renal failure, characters of primary AVF, and variables of endovascular intervention (e.g., clinical success and complications), primary patency, and recurrence of stenosis .

Patients were examined by Duplex Ultrasound as it was considered abnormal in cases of greater than 50 percent stenosis of the feeding artery or outflow vein or in cases of decreased flow rate (less than $500 \mathrm{~mL} /$ minute) before fistulography for diagnosis of AVF stenosis .
Fistulography was carried out through brachial artery puncture with a $21 \mathrm{G}$ needle and injection of $10 \mathrm{~mL}$ of radio-contrast substance under local anesthesia. Images were recorded for feeding artery, arteriovenous anastomosis, a juxta-anastomotic segment of the efferent, and draining veins up to the central veins. The stenosis was assessed by comparison between the stenotic and adjacent normal segments of the veins together, with the application of balloon angioplasty for the stenotic segments with a diameter of $<50$ percent of the normal segment .

Balloon angioplasty was done using an endo-venous procedure (Antegrade and Retrograde manner). Access was done through the outflow vein with $5 \mathrm{~F}$ vascular sheath insertion. Heparin was injected by a dose of $2500 \mathrm{IU}$ (and an additional dose of $1250 \mathrm{IU}$ was injected every hour, if needed, with a maximum dose of $5000 \mathrm{IU})$. The determination of the balloon size was done according to the measured diameter of the reference vessel.

A standard balloon (Boston Scientific Inc., 300 Boston Scientific Way Marlborough, Massachusetts, USA) with a diameter of $1 \mathrm{~mm}$ larger than the normal size of the venous segment $(4-8 \mathrm{~mm})$ was used. The insufflation of the balloon was sustained for $2 \mathrm{~min}$, and the technique was repeated if needed. Stenting was done in two cases, to overcome the recoil of the stenotic lesion(case of central venous stenosis) and to control venous rupture, this was done by passing the stent over the wire till the stenotic lesion becomes in the middle of the stent which is then inflated and deployed carefully in order not to lose its place

If stenosis became $<30 \%$ after balloon angioplasty, the technical success of the procedure would be documented. Manual compression was used to achieve hemostasis after the removal of the sheath .

Clinical success was recognized as adequate dialysis after the procedure. Regular outpatients follow up visits were arranged for each patient every two weeks for the first 2 months, then every month for 6 months. This follow up was done clinically and radiologically (using venous mapping and $\$ or angiography if restenosis that was suspected based on clinical examination or dialysis parameters) to ensure the patency of the vascular access and the probability of restenosis

Primary patency was defined as the time interval between the balloon angioplasty and the subsequent thrombosis or repeated intervention, as defined by Gray et al. ${ }^{11}$

\section{Statistical analysis:}

The collected data were organized, coded, and analyzed by statistical package for social science for windows, Version 20.0 (IBM Corp., Armonk, NY, USA). For categorical variables, Fisher's exact test, Pearson Chi-square tests, independent samples $(t)$, and Mann- Whitney U test was used for numerical data. Data were presented as mean \pm standard deviation (SD), minimum-maximum values, number (n) and percentage (\%) according to the type of data. 
A value of $\mathrm{p}<0.05$ was considered statistically significant.

\section{RESULTS}

In this study, the patient's age varied from 23 to 89 years. The mean age is 60.5 .25 males $(62.5 \%)$ and 15 females $(37.5 \%)$ are included . Risk factors were in the form of smoking (44.0\%), diabetes mellitus (72.0\%), hypertension (84.0\%), and coronary artery disease $(32.0 \%)$. The primary AVF type was brachiocephalic $(57.5 \%)$, brachiobasilic $(32.5 \%)$ and radiocephalic (10.0\%). Fistulography revealed peripheral venous stenosis in 18 patients $(45.0 \%)$, central venous stenosis in 14 patients $(35.0 \%)$, and juxta-anastomotic stenosis in 8 patients (20\%).

Regarding endovascular intervention were done through a transvenous retrograde approach in 23 cases $(57.5 \%)$ and trans-venous Antegrade approach in 17 cases $(42.5 \%)$, the percent of stenosis varies from mild stenosis to total occlusion. Consequently, multiple interventional procedures were done. 38 cases needed angioplasty ( $95 \%$ of cases), and 2 cases needed stent placement (5\% of cases).

Regarding the outcome of endovascular intervention, after the interventional procedures were done, estimation of the outcome of the procedure is done via visual estimation of the residual stenosis; in 4 cases $(10 \%)$ there was no residual stenosis, in 7 cases $(17.5 \%)$ there was $<10 \%$ residual stenosis, in 24 cases $(60.0 \%)$ there was $<30 \%$ residual stenosis and in 5 cases $(12.5 \%)$ there was $>30 \%$ residual stenosis. Finally, we report that the technical success (no residual stenosis or $<30$ percent), and early clinical success was achieved in (87.5\%) of cases; the patency rate was $91.0 \%$ in a month, $86.0 \%$ in 3 months and $80.0 \%$ in 6 months. The procedure complications were vascular spasm in 4 patients $(10.0 \%)$, puncture site hematoma in 3 patients (7.5\%), extravasation in 2 patients $(5.0 \%)$ that were treated conservatively, and rupture of the vessel wall in 1 patient that need stenting. The recurrence (restenosis) during follow up period was reported after one month in $7.5 \%$ of cases ( 3 patients), after 3 months in $12.5 \%$ of cases ( 5 patients) however after 6 months in $17.5 \%$ of cases ( 7 patient). The time to recurrence ranged from 105 to 210 days with a mean duration of $167.14 \pm 34.13$ days (Table $1-10$ ).

In the present work, recurrence was significantly associated with older age (as patients with recurrence were significantly older than those without recurrence $(62.44 \pm 1.87$ vs $54.37 \pm 7.13$ years respectively)) and the increased coronary artery disease (CAD was reported in $55.6 \%$ of patient with recurrence compared to $18.8 \%$ of patients without recurrence). Otherwise, no significant association was found between recurrence and patient gender, other risk factors, AVF type, or fistula segment. Examples of studied cases were presented in (Figures 1-3).

\begin{tabular}{|l|c|c|l|} 
Gender & No & $\%$ & \multicolumn{1}{c|}{ Age } \\
\cline { 1 - 3 } Male & 25 & $62.5 \%$ & $\begin{array}{l}\text { 23-89years (mean } \\
\text { age 60.5 years) }\end{array}$ \\
\cline { 1 - 3 } Female & 15 & $37.5 \%$ & \\
\hline
\end{tabular}

Table 1: Demographic data (gender and number of patients).

\begin{tabular}{|l|c|l|} 
Etiology & No & $\%$ \\
\hline Smoking & 11 & $44.0 \%$ \\
\hline Diabetes mellitus & 18 & $72.0 \%$ \\
\hline Hypertension & 21 & $84.0 \%$ \\
\hline Coronary artery disease & 8 & $32.0 \%$ \\
\hline
\end{tabular}

Table 2: Etiology \& Risk factors of ESRD of patient.

\begin{tabular}{|l|c|l|}
\hline Type of failing AVFs & No & $\%$ \\
\hline Radio cephalic & 4 & $10.0 \%$ \\
\hline Brachio cephalic & 23 & $57.5 \%$ \\
\hline Brachiobasalic & 13 & $32.5 \%$ \\
\hline
\end{tabular}

Table 3: Primary AVF type.

\begin{tabular}{|l|c|c|}
\hline & No & \% \\
\hline Inefficient dialysis & 12 & $30 \%$ \\
\hline weak thrill & 11 & $28 \%$ \\
\hline Increased venous pressure & 8 & $20 \%$ \\
\hline Arm edema & 9 & $22 \%$ \\
\hline
\end{tabular}

Table 4: Clinical Finding on detection of Failed Fistula.

\begin{tabular}{|l|c|c|}
\hline \multicolumn{2}{|c|}{ No } & $\%$ \\
\hline juxta anastomotic stenosis & 8 & $20 \%$ \\
\hline Peripheral Venous stenosis & 18 & $45.0 \%$ \\
\hline Central Venous stenosis & 14 & $35.0 \%$ \\
\hline
\end{tabular}

Table 5: Sites of stenosis found on the angiographic assessment.

\begin{tabular}{|l|c|c|l|}
\hline \multicolumn{2}{|c|}{ No } & $\%$ \\
\hline $\begin{array}{l}\text { Trans venous } \\
\text { approach }\end{array}$ & 17 & $42.5 \%$ \\
\hline $\begin{array}{l}\text { Trans venous Retre grade } \\
\text { approach }\end{array}$ & 23 & $57.5 \%$ \\
\hline
\end{tabular}

Table 6: Types of access for endovascular intervention. 


\begin{tabular}{|l|c|l|}
\hline & No & $\%$ \\
\hline Angioplasty & 38 & $95.0 \%$ \\
\hline Stenting & 2 & $5.0 \%$ \\
\hline
\end{tabular}

Table 7: Types of Interventional procedures.

\begin{tabular}{|c|c|c|}
\hline \multicolumn{2}{|c|}{ Residual stenosis (\%) } & No \\
\hline $0 \%$ & 4 & $10.0 \%$ \\
\hline$<10 \%$ & 7 & $17.5 \%$ \\
\hline$<30 \%$ & 24 & $60.0 \%$ \\
\hline$>30 \%$ & 5 & $12.5 \%$ \\
\hline
\end{tabular}

Table 8: Residual stenosis after the procedures.

\begin{tabular}{|l|c|l|}
\hline \multicolumn{2}{|c|}{ No } \\
\hline None & 30 & $75.0 \%$ \\
\hline Vascular spasm & 4 & $10.0 \%$ \\
\hline Hematoma at site of puncture & 3 & $7.5 \%$ \\
\hline Extravasation & 2 & $5.0 \%$ \\
\hline Rupture of vessel wall & 1 & $2.5 \%$ \\
\hline
\end{tabular}

Table 9: Complications of the procedure.

\begin{tabular}{|l|c|l|}
\hline \multicolumn{2}{|c|}{ No } & $\%$ \\
\hline After 1 months & 32 & $91.0 \%$ \\
\hline After 3 months & 30 & $86.0 \%$ \\
\hline After 6 months & 28 & $80.0 \%$ \\
\hline $\begin{array}{l}\text { Time to recurrence } \\
\text { (days) }\end{array}$ & $\begin{array}{l}167.14 \pm 34.13 ; 105- \\
210\end{array}$ \\
\hline
\end{tabular}

Table 10: Primary patency rate.

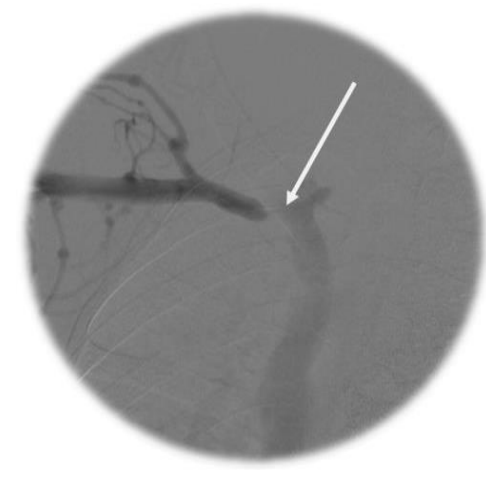

(a)

(b)

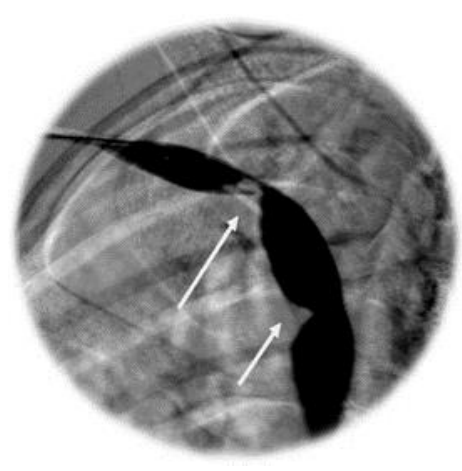

(c)

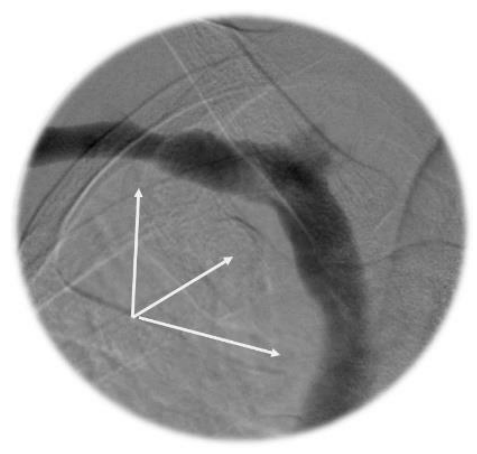

Fig. 1: Venography of the right subclavian and innominate vein showing stenosis of the innominate vein (a), wasting of the balloon (b), and dilatation of the stenosis after balloon angioplasty (technical success) (c).

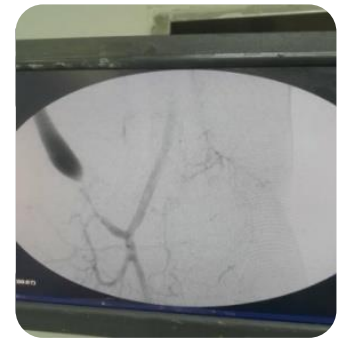

(a)

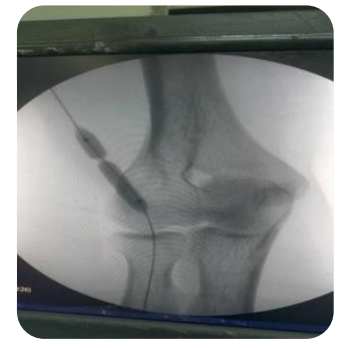

(c)
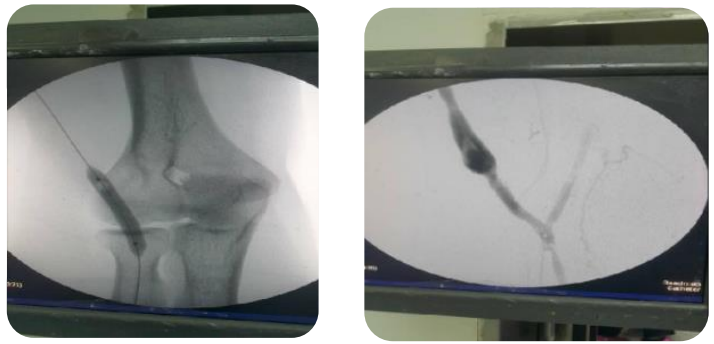

(d)

Fig. 2: Diagnostic angiogram shows combined lesions of BC AVF(a), Balloon dilatation showing significant waist (b), Good balloon dilatation Without waist (c), and Final angiogram good dilation with good filling(d). 


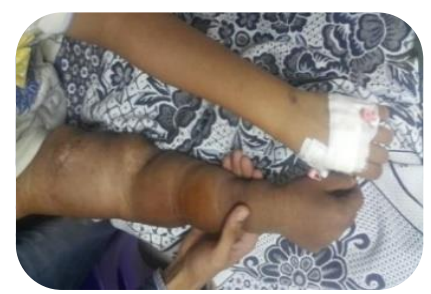

(a)

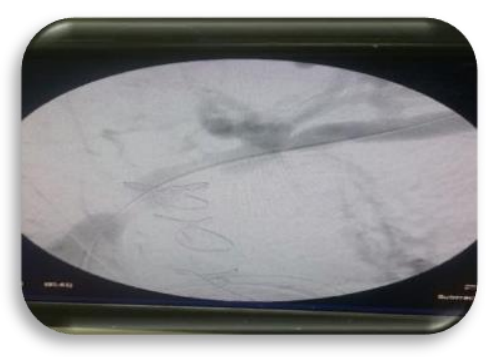

(d)

(b)

(e)

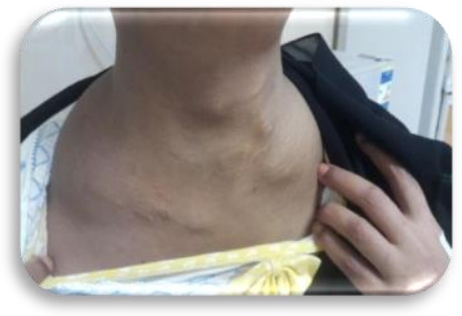

(c)

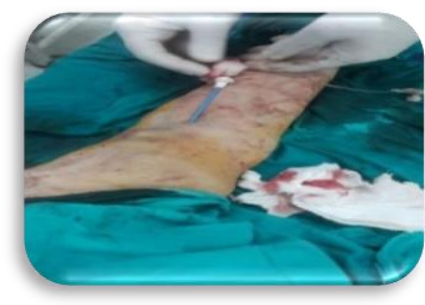

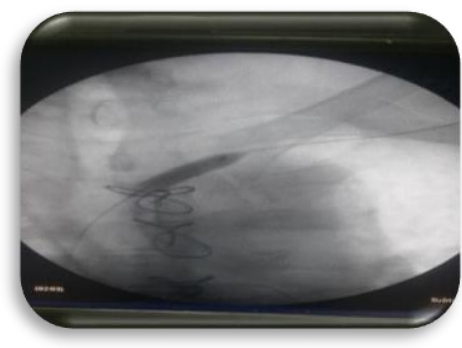

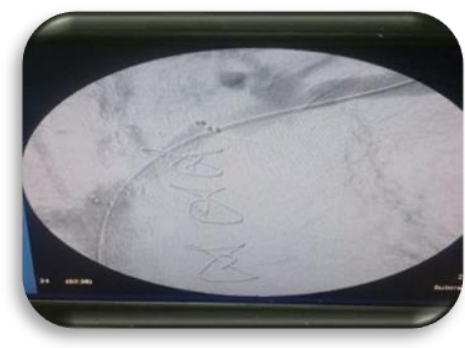

(f)

Fig. 3: RT arm swelling 2ry to venous HTN (a), neck swelling and dilated veins (b), Trans-venous access using sheath 6 Fr (c), innominate vein stenosis (d), balloon dilation and restenosis (e), and SES placement wall stent (Bard) with good flow and patency (f).

\section{DISCUSSION}

The creation of patent arteriovenous fistula considered as the cornerstone for the starting of hemodialysis which is the mainstay in the treatment of chronic (ESRD) (waiting or unfit for renal transplant). The prevalence of end-stage renal disease increases with an increased life expectancy of patient with ESRD. Thus, maintaining patency of AVF is crucial for those patients. ${ }^{12}$ AVF maturation includes remodeling of the vessel wall, feeding artery enlargement, and arterialization of the vein due to higher blood flow and blood pressure. ${ }^{13}$ Failure to mature the fistula may be occurred and recognized by inadequate AVF flow to sustain hemodialysis after 6 weeks of maturation, with an incidence rate of up to $60 \% .^{7}$

The kidney disease outcomes quality initiative (KDOQI) guidelines recommend an arteriovenous fistula (AVF) as the guide standard for primary vascular access due to increased life expectancy and a reduced rate of infection compared to an arteriovenous graft (AVG). However, several studies showed that surgically created AVFs have high rates of early failure, such patient frequently need surgical or endovascular treatment. ${ }^{14}$

Here, we presented our clinical experience with the treatment of stenosed, non-mature native AVF with the endovascular intervention (balloon angioplasty and stenting). Results of the present work showed that endovascular intervention is effective (technical success was $87.5 \%$ with a patency rate of $91.0 \%$ in a month, $86.0 \%$ in 3 months and $80.0 \%$ in 6 months after the procedure, and safe (complication rate was $15.0 \%$ ) which were vascular spasm in $10.0 \%$ of cases (4 patient), puncture site hematoma in $7.5 \%$ of cases ( 3 patient), extravasation in $5.0 \%$ of cases ( 2 patient) that were treated conservatively and rupture of the vessel wall in $7.5 \%$ of cases (1 patient) that needed stenting. The associated factors with recurrence were the patient's age and coronary artery disease.

Ascher et al. ${ }^{15}$, Gallagher et al. ${ }^{16}$, Derderian et al. ${ }^{17}$, and Rizvi et al. ${ }^{18}$ reported that balloon angioplasty to assist maturation is usually used for treat stenotic non-matured AVF under angiography or ultrasound guidance. They reported a success rate ranged between $55 \%$ to $89 \%$.Derderian et al. ${ }^{19}$ reported that the most common complications were hematoma $(40 \%)$, extravasation ( $9 \%)$, the formation of puncture site hematoma (4\%), and thrombosis (2\%).

In AlGaby et al. ${ }^{20}$ research concerning the results of our procedure, it was discussed as an immediate technical success during the intervention and clinical success after PTA with follow-up of each patient for one year as technical success was $80 \%(n=16)$ and clinical success was $60 \%(n=14)$, as regards the procedural complications, the results showed that complications during PTA occurred in $20 \%$ of 20 patient $(n=4)$ who had minor venous perforation with extravasation of contrast, which was self-limited with no need for intervention. However, this technical 
success was close to the results of Heye et al. ${ }^{21}$ $(84.4 \%)$.

In contrast, Aktas et al. ${ }^{22}$ had a technical success of 96.3\% of overall stenosis (without occlusion) and a first-year patency rate of $84.7 \%$.

Aborahma A. ${ }^{23}$ conducted study on 37 patient, achieved the overall technical success in $86.4 \%$ (32) of cases and early clinical success was complete in all these cases except in one case with non-mature fistula as after successful dilatation of radial artery the fistula didn't mature and the access was withdrawn and another access was established. Primary patency in 1 month, 3 month and 6 months were $93.8 \%$ (30/32), $71.8 \%(23 / 32)$, and $62.5 \%$ (20/32) respectively, the secondary patency in 1 month, 3 months and 6 months were $93.8 \%$ (30/32), $78.1 \%(25 / 32)$ and $68.8 \%(22 / 32)$ respectively. As regards the procedural complications he reported vessel wall rupture in (3) patient, which was easily managed by sustained low pressure inflation of the balloon.There was no hematoma on the entry site and no stent migration was observed.

In an observational prospective trial, Beathard et al.4 included one hundred patients with early non-mature AVF were included with stenosis in $78 \%$, with $48 \%$ of these lesions reported to be near to the anastomosis (Juxta-anastomotic). Percutaneous balloon dilatation was conducted with a $98.0 \%$ success rate. Upon follow up, $84 \%$ of the AVF was functioning in 3 months, $72 \%$ in 6 months, and $68 \%$ in 12 months. The complications rate was $4 \%$. Only one patient $(1 \%)$ had a vein rupture (major complication) with an increasing hematoma and subsequent loss of the access. The other complications were low-grade hematomas that did not require any special intervention .

Shah and Agarwal ${ }^{24}$ advocated the assessment of recently developed AVF in 4-6 weeks after creation to discover individuals with early AVF nonmaturation (failure). Clinical evaluation is an easy but effective technique to discover such patient with AVF failure and should be confirmed by duplex ultrasound. Once discovered, these patients should undergo appropriate intervention use of percutaneous endovascular procedures such as balloon angioplasty and vein obliteration. We added that much of the non-maturation of early fistula can be salvaged.

\section{CONCLUSION}

Endovascular salvage of failing A-V fistulas with PTA is both effective and relatively safe. It is associated with high success rates, low complication rates, decreasing the need for hospitalization, rendering the immediate reuse of the failing fistula with good results, and maintained long-term patency .

Endovascular techniques have tended to supplant traditional surgery at many centers. Percutaneous therapies including angioplasty and the use of stents have made access repair easier, more successful, less invasive, and readily available on an outpatient basis.

\section{REFERENCES}

1. Almasri J, Alsawas $\mathrm{M}$, Mainou $\mathrm{M}$, et al. Outcomes of vascular access for hemodialysis: a systematic review and meta-analysis. J Vasc Surg 2016; 64:236-43.

2. Leermakers JJ, Bode AS, Vaidya A,et al.Costeffectiveness of vascular access for haemodialysis: arteriovenous fistulas versus arteriovenous grafts. Eur J VascEndovasc Surg 2013; 45:84-92.

3. Hicks CW, Canner JK, Arhuidese I, et al. Mortality benefits of different hemodialysis access types are age-dependent. J Vasc Surg 2015; 61:449-56.

4. Beathard GA, Arnold P, Jackson J, et al. Aggressive treatment of early fistula failure. Kidney Int. 2003; 64:1487-94.

5. Beathard GA. Angioplasty for arteriovenous grafts and fistulae. Semin Nephrol 2002; 22:20210 .

6. Lok CE, Allon M, Moist L, et al. Risk equation determining unsuccessful cannulation events and failure to maturation in arteriovenous fistulas (REDUCE FTM I). J Am Soc Nephrol 2006;17: 3204-12.

7. Dember LM, Beck GJ, Allon M, et al. Dialysis Access Consortium Study Group. Effect of clopidogrel on early failure of arteriovenous fistulas for hemodialysis: a randomized controlled trial. JAMA 2008;299: 2164-71.

8. Wilmink T, Hollingworth L, Powers S, et al. Natural history of common autologous arteriovenous fistulae: consequences for planning of dialysis. Eur J VascEndovasc Surg 2016; 51:134-40.

9. Masengu A, Maxwell AP, Hanko JB. Investigating clinical predictors of arteriovenous fistula functional patency in a European cohort. Clin Kidney J 2016; 9:142-47.

10. Tordoir JHM, Zonnebeld N, van Loon MM, et al. Surgical and endovascular intervention for dialysis access maturation failure during and after arteriovenous fistula surgery:a review of the evidence. Eur J VascEndovasc Surg 2018; 55: 240-48.

11. Gray RJ, Sacks D, Martin LG, et al. Reporting standards for percutaneous interventions in dialysis access. J VascIntervRadiol. 2003; 14:433-42.

12. Forsythe RO andChemla ES. Surgical Options in the Problematic Arteriovenous Hemodialysis Access. Cardiovasc Intervent Radiol 2015; 38:1405-15.

13. Corpataux JM, Haesler E, Silacci P, et al. Lowpressure environment and remodeling of the forearm vein in Brescia-Cimino haemodialysis access. Nephrol Dial Transplant. 2002; 17:10576. 
14. Canaud, B., Ponce, P., Teresa Parisotto, M., et al. Vascular Access Management for Haemodialysis: A Value-Based Approach from NephroCare Experience. Vascular Access Surgery - Tips and Tricks 2019.

15. Ascher E, Hingorani A and Marks N. Duplexguided balloon angioplasty of failing or nonmaturing arterio-venous fistulae for hemodialysis: a new office-based procedure. $J$ Vasc Surg 2009; 50:594-9.

16. Gallagher JJ, Boniscavage $\mathrm{P}$, Ascher E, et al. Clinical experience with office-based duplex guided balloon-assisted maturation of arteriovenous fistulas for hemodialysis. Ann Vasc Surg 2012; 26:982-4.

17. Derderian T, Hingorani A, Ascher E, et al. To BAM or not to BAM? A closer look at balloonassisted maturation. Ann Vasc Surg 2013; 27:104-9.

18. Rizvi SA, Usoh F, Hingorani A, et al. The clinical efficacy of balloon-assisted maturation of autogenous arteriovenous fistulae. Ann Vasc Surg 2015; 41:41-5.

19. Derderian T, Hingorani A, Boniviscage $P$, et al.Acute complications after balloon-assisted maturation. Ann Vasc Surg 2014; 28:1275-9.

20. AlGaby AZ, Marzouk AA, Shawky K, et al.Failing arteriovenous access: endovascular option. Egypt J Surg; 2019;38:231-8.

21. Heye S, Maleux G, Vaninbroukx J, et al.Factors influencing technical success and outcome of percutaneous balloon angioplasty in de novo native hemodialysis arteriovenous fistulas. Eur $J$ Radiol 2012; 81:2298-303 .

22. Aktas A, Bozkurt A, Aktas B, et al. Percutaneous transluminal balloon angioplasty in stenosis of native hemodialysis arteriovenous fistulas: technical success and analysis of factors affecting postprocedural fistula patency. Diagn IntervRadiol 2015; 21:160-6.

23. Aborahama A and Ismail AM. Endovascular Management of Failing Arteriovenous Fistula.Egjves 2015; 11: 284.

24. Shah R and Agarwal AK. Approach to a Patient with Nonmaturing AV Fistula. Interventional Nephrology. Springer, New York, NY, 2014. 939. 